\title{
Tea saponin reduces the damage of Ectropis obliqua to tea crops, and exerts reduced effects on the spiders Ebrechtella tricuspidata and Evarcha albaria compared to chemical insecticides
}

Chi Zeng ${ }^{1}$, Lingbing Wu ${ }^{1}$, Yao Zhao ${ }^{1}$, Yueli Yun ${ }^{1}$, Yu Peng ${ }^{\text {Corresp. } 1}$ 1 Hubei Collaborative Innovation Center for Green Transformation of Bio-Resources, College of Life Science, Hubei University, Wuhan, Hubei, People's
Republic of China

Corresponding Author: Yu Peng

Email address: pengyu@hubu.edu.cn

Background. Tea is one of the most economically important crops in China. However, the tea geometrid (Ectropis obliqua), a serious leaf-feeding pest, causes significant damage to tea crops and reduces tea yield and quality. Spiders are the most dominant predatory enemies in the tea plantation ecosystem, which makes them potentially useful biological control agents of $E$. obliqua. These highlight the need for alternative pest control measures. Our previous studies have shown that tea saponin (TS) exerts insecticidal activity against lepidopteran pests. Here, we investigate whether TS represents a potentially new alternative insecticide with no harm to spiders. Methods. We investigated laboratory bioactivities and the field control properties of TS solution against $E$. obliqua. (i) A leaf-dip bioassay was used to evaluate the toxicity of TS to 3rd-instar E. obliqua larvae and effects of TS on the activities of enzymes glutathione-S-transferase (GST), acetylcholinesterase (AChE), carboxylesterase (CES) and peroxidase (POD) of 3rd-instar $E$. obliqua larvae in the laboratory. (ii) Topical application was used to measure the toxicity of $30 \%$ TS (w/v) and two chemical insecticides (10\% bifenthrin EC and 50\% diafenthiuron SC) to two species of spider, Ebrechtella tricuspidata and Evarcha albaria. (iii) Field trials were used to investigate the controlling efficacy of $30 \%$ TS against $E$. obliqua larvae and to classify the effect of TS to spiders in the tea plantation. Results. The toxicity of TS to 3rdinstar E. obliqua larvae occurred in a dose-dependent manner and the $\mathrm{LC}_{50}$ was 164.32 $\mathrm{mg} / \mathrm{mL}$. Activities of the detoxifying-related enzymes, GST and POD, increased in 3rd-instar E. obliqua larvae, whereas AChE and CES were inhibited with time by treatment with TS. Mortalities of E. tricuspidata and E. albaria after $48 \mathrm{~h}$ with $30 \%$ TS treatment $(16.67 \%$ and $20 \%$, respectively) were significantly lower than those with $10 \%$ bifenthrin EC $(80 \%$ and $73.33 \%$, respectively) and 50\% diafenthiuron EC (43.33\% and $36.67 \%$, respectively). The highest controlling efficacy of $30 \%$ TS was $77.02 \%$ at $5 \mathrm{~d}$ after treatment, which showed no 
difference to $10 \%$ bifenthrin EC or $50 \%$ diafenthiuron SC. $30 \%$ TS was placed in the class N (harmless or slightly harmful) of IOBC (International Organization of Biological Control) categories for natural enemies, namely spiders. Conclusions. Our results indicate that TS is a botanical insecticide that has a good controlling efficacy in E. obliqua larvae, which suggests it has promise as application in the integrated pest management (IPM) envisaged for tea crops. 
1 Tea saponin reduces the damage of Ectropis obliqua to tea

2 crops, and exerts reduced effects on the spiders Ebrechtella

3 tricuspidata and Evarcha albaria compared to chemical

4 insecticides

5

6

7 Chi Zeng, Lingbing Wu, Yao Zhao, Yueli Yun, Yu Peng

8

9

10

11 Hubei Collaborative Innovation Center for Green Transformation of Bio-Resources, College of

12 Life Sciences, Hubei University, Wuhan 430062, P. R. China

13

14

15 Corresponding author

16 Yu Peng

17

18 E-mail address: pengyu@hubu.edu.cn

19

20

21 
24

\section{Abstract}

Background. Tea is one of the most economically important crops in China. However, the tea geometrid (Ectropis obliqua), a serious leaf-feeding pest, causes severe damage to tea crops and reduces tea yield and quality. Spiders are the most dominant predatory enemies in the tea plantation ecosystem, which makes them potentially useful biological control agents of E. obliqua. Under these circumstances, the need for alternative pest control strategy are highlight. It has been shown in our previous study that tea saponin (TS) has insecticidal activity against lepidopteran pests. Here, we investigate whether TS represents a potentially new alternative insecticide with no harm to spiders.

Methods. We investigated two properties of TS solution which was applied against E. obliqua larvae, including its bioactivities in the laboratory and controlling efficacy in the field. (i) A leafdip bioassay was used to evaluate the toxicity of TS to 3rd-instar E. obliqua larvae and effects of TS on the activities of enzymes glutathione-S-transferase (GST), acetylcholinesterase (AChE), carboxylesterase (CES) and peroxidase (POD) of 3rd-instar E. obliqua larvae in the laboratory. (ii) Topical application was used to detect the toxicity of $30 \% \mathrm{TS}(\mathrm{w} / \mathrm{v})$ and two chemical insecticides (10\% bifenthrin EC and 50\% diafenthiuron SC) to spiders, Ebrechtella tricuspidata and Evarcha albaria. (iii) Field trials were used to investigate the controlling efficacy of $30 \%$ TS against $E$. obliqua larvae and to classify the effect of TS on spiders in the tea plantation.

Results. The toxicity of TS to 3rd-instar E. obliqua larvae occurred in a dose-dependent manner 
43 and the $\mathrm{LC}_{50}$ was $164.32 \mathrm{mg} / \mathrm{mL}$. Activities of the detoxifying-related enzymes, GST and POD,

44 increased in 3rd-instar E. obliqua larvae, whereas the activities of AChE and CES, after treatment

45 with TS, were inhibited with time. After 48 h, mortalities of E. tricuspidata and E. albaria with

$4630 \%$ TS treatment ( $16.67 \%$ and $20 \%$, respectively) were significantly lower than those with $10 \%$

47 bifenthrin EC (80\% and 73.33\%, respectively) and 50\% diafenthiuron EC (43.33\% and 36.67\%,

respectively). The highest controlling efficacy of $30 \%$ TS was $77.02 \%$ on $5 \mathrm{~d}$ after treatment,

which showed no difference to $10 \%$ bifenthrin EC or $50 \%$ diafenthiuron SC. $30 \%$ TS was placed

in the class $\mathrm{N}$ (harmless or slightly harmful) of IOBC (International Organization of Biological

Control) categories for natural enemies, namely spiders.

Conclusions. Our results indicate that TS is a botanical insecticide that exhibits good controlling

efficacy in E. obliqua larvae, which suggests it has promise to be applied in the integrated pest

management (IPM) envisaged for tea crops.

\section{Introduction} important crops in China, cultivated in vast areas spreading from $37^{\circ} \mathrm{N}-18^{\circ} \mathrm{S}$ and $122^{\circ} \mathrm{E}-97^{\circ}$

$\mathrm{W}$, totaling more than 20 provinces across tropical, subtropical and temperate regions (Ye et al., 2014). The tea geometrid, Ectropis obliqua (Lepidoptera: Geometridae), is a major pest throughout tea plantations in China (Zhang et al., 2014). Its larvae exclusively feed on tea leaves and tender buds, causing severe deterioration in yield and quality (Ma et al., 2016). The therapeutic approach of killing this pest with chemicals has been the prevailing control strategy (Hazarika, Puzari \& 
64 Wahab, 2001; Ehi-Eromosele, Nwinyi \& Ajani, 2013; Xin et al., 2016). However, indiscriminate

65

66

67

use of chemicals in tea gardens has given rise to a large number of problems, including resurgence of primary pests (Harmatha et al., 1987), resistance development (Gurusubramanian et al., 2008), undesirable residues in tea products (Feng et al., 2013) and environmental contamination (Saha \& Mukhopadhyay, 2013; Ye et al., 2014).

Botanical insecticides are superior to traditional chemical pesticides in terms of several ecotoxicological indicators, i.e. low toxicity to human, rapid degradation, reduced environmental impact (Bourguet, Genissel \& Raymond, 2000; Isman, 2006; Chermenskaya et al., 2010) as well as multiple bioactivities. Through deterring oviposition and feeding, regulating growth and being toxic to larvae and adults, they represent an alternative for pest control (Isman, 2006; Chermenskaya et al., 2010; Martínez et al., 2015). These advantages indicate that botanical insecticides can be an ideal option for managing pests in an eco-friendly and economical way (Abou-Fakhr, Zournajian \& Talhouk, 2001; Isman, 2006; Roy, Mukhopadhyay \& Gurusubramanian, 2010; Martínez et al., 2015).

Tea saponin (TS) is extracted from the seeds of plant species belonging to the genus Camellia of the family Theaceae, and it can enhance efficiency and solubilization of pesticide as a wetting powder pesticide (Chen, Zhang \& Yang, 2012). TS has been widely used in pesticides as the main component of environmentally-friendly pesticide additives (De Geyter et al., 2007). Chaieb (2010) concluded that the insecticidal activity of saponins is due to a disturbance of the synthesis of ecdysteroids, protease inhibitors or cytotoxic to certain insects. TS, which has a strong insecticidal activity against a broad range of insect types and stages, has potential to be used as a natural 
85

86

87

88

89

90

insecticide (Potter et al., 2010; Cai et al., 2016). In our previous studies, we found that $30 \%$ TS (w/v; $300 \mathrm{mg} / \mathrm{mL}$ ) exerted a strong toxic effect on E. obliqua larvae (Hao et al., 2011; Liu et al., 2012).

Biological control has gained recognition as an essential component of successful integrated pest management (IPM) (Murphy \& Briscoe, 1999; Jacobsen, Zidack \& Larson, 2004; Yang et al., 2017). Predatory natural enemies play key functional roles in the biological control of IPM (Rutledge, Fox \& Landis, 2004), and spiders are the most dominant predatory natural enemies in the tea plantation ecosystem (Chen et al., 2004; Das, Roy \& Mukhopadhyay, 2010). Hu et al. (1994) used feeding trials in the laboratory to show that Ebrechtella tricuspidata and Evarcha albaria prey on the larvae of E. obliqua. Yang et al. (2017) have demonstrated that these two species exhibit maximum potential in taking control of E. obliqua larvae, which will be disturbed if chemicals with adverse effects are used. Allowing for that, it has become necessary to find alternative, as well as effective biodegradable insecticides with greater acceptability than chemical insecticides (Roy, Mukhopadhyay \& Gurusubramanian, 2010).

The physiological and metabolic functions of insects have frequently been reported to be influenced by chemicals or host plant variety (Cai et al., 2016). Likewise, insects are defended against insecticides via multiple enzyme systems (Terriere, 1984; Serebrov et al., 2006). Karban et al. (2002) suggested that herbivore insects are adapted to host secondary substances through physiological changes. In that case, the metabolism of plant secondary substances and chemical pesticides through enzyme systems are usually considered to be identical or similar (Brattsten, 1988; Snyder \& Glendining, 1996). Various detoxification enzymes such as glutathione-S- 
106

107

108

109

110

111

112

113

114

115

116

117

118

119

120

121

122

123

124

125

126

transferase (GST) and carboxylesterase (CES) are most commonly involved in insects defense

against insecticides (Serebrov et al., 2006). Acetylcholinesterase is a key enzyme catalyzing the hydrolysis of the neurotransmitter, acetylcholine, in the nervous system in various organisms (Oehmichen \& Besserer, 1982; Wang et al., 2004). It is well-known that altered AChE is one of the main mechanisms of resistance in many insect pests that are affected by chemical and botanical insecticides (Miao et al., 2016). Peroxidase (POD) is an antioxidant enzyme that can provide defense against pathogens and insecticides (Felton \& Summers, 1995; Miao et al., 2016). Previous studies have demonstrated that POD can be quickly up-regulated in response to xenobiotic threats and that increased activity of this enzyme is related to pesticide resistance (Miao et al., 2016).

Therefore, the biological traits of TS prompt us to test if: (i) TS exerts a strong lethal effect on the pest E. obliqua, while being non-toxic to predators such as E. tricuspidata and E. albaria in the laboratory; (ii) the multiple enzyme system in 3rd-instar E. obliqua is involved in defending the larvae against TS; (iii) $30 \% \mathrm{TS}$ (w/v) shows effective control of E. obliqua larvae and does not harm natural enemies in tea plantations.

\section{Material and Methods}

\section{Test insects and spiders}

Larvae of E. obliqua, together with E. obliqua, spiderlings of E. tricuspidata and E. albaria were originally collected from tea bushes at the Wang Dazhen tea plantation $\left(30.011^{\circ} \mathrm{N}, 114.363^{\circ}\right.$ E), Xianning, Hubei Province, China, from May to October 2014. The total area of the collection site is about 6.5 ha with parallel rows of tea plants about $100 \mathrm{~m}$ long and $1 \mathrm{~m}$ apart (Fig. S1). The 
127 site is an organic tea plantation in which no insecticides have been applied. E. obliqua Larvae were

128 fed on fresh tea leaves and reared for 5 generations in self-made plastic chambers $(10 \mathrm{~cm}$ diameter

$129 \times 10 \mathrm{~cm}$ height) at $28 \pm 1{ }^{\circ} \mathrm{C}$ and $75 \pm 5 \%$ relative humidity under a 14-h light:10-h dark

130 photoperiod in the Centre for Behavioral Ecology and Evolution (College of Life Sciences, Hubei

131 University). A chamber was used for rearing 10 larvae, and 3rd-instar larvae of E. obliqua were

132 used in the following experiments.

133 Spiders were kept individually in glass tubes $(1.5 \mathrm{~cm}$ diameter $\times 10 \mathrm{~cm}$ length $)$. Each glass

134 tube was blocked with a cotton plug and included $1 \mathrm{~cm}$ of moist sponge at the bottom to maintain

135 high humidity. The tubes were kept in an illumination incubator $\left(25 \pm 1{ }^{\circ} \mathrm{C}, 75 \pm 5 \%\right.$ relative

136 humidity and under a 14-h light:10-h dark photoperiod). Wild-type fruit flies (Drosophila

137 melanogaster) were provided twice a week as food. Adult spiders of similar size were used for the

138 toxicity tests.

139

140

Reagents

Tea saponin (98\% purity) was purchased from Wuhan Bai Ming Technology Co., Ltd, Hubei

province, China. 10\% bifenthrin (Bi) EC and 50\% diafenthiuron (Di) SC were purchased from

Jiangsu Dongbao Chemical Corporation Ltd., Jiangsu province, China. Both of these chemical

insecticides are of low toxicity and are widely applied in the tea growing area in China to control

leaf-feeding insects (Wu et al., 2013; Liu 2014). 
147 Toxicity of TS to E. obliqua larvae

The leaf-dip bioassay method described by Beloti et al. (2015) and Liang et al. (2003) was adopted for the toxicity assay in which the toxicity of TS to 3rd-instar E. obliqua larvae was assayed. We evaluated five TS concentrations $(18.75,37.5,75,150$ and $300 \mathrm{mg} / \mathrm{mL})$. Distilled water was used to prepare the dilutions. Tea leaf discs (diameter $4 \mathrm{~cm}$ ) were dipped for $20 \mathrm{~s}$ in one of the TS concentrations. Then, the leaf discs were dried by placing them in a glass Petri dish (diameter $9 \mathrm{~cm}$ ). Leaf discs in control group were dipped in distilled water as described above. Thirty 3rd-instar E. obliqua were starved for $24 \mathrm{~h}$ and then transferred to the glass Petri dish (two leaves per Petri dish). Three replicates were made for each concentration. Larvae were considered to be dead if they did not respond when lightly prodded with a hair brush. Larvae mortality (\%) were quantified after $48 \mathrm{~h}$ of treatment. Surviving larvae were, within $1 \mathrm{~h}$, used for the following enzyme activity assays.

\section{Toxicity of insecticides to spiders}

For the insecticide treatment, TS powder was diluted with distilled water to a concentration of $300 \mathrm{mg} / \mathrm{mL} ; 10 \%$ Bi EC and 50\% Di EC were diluted with distilled water to concentration of $0.01 \mathrm{mg} / \mathrm{mL}$ and $0.05 \mathrm{mg} / \mathrm{mL}$ (advised by the manufacturer of the chemicals), respectively. Prior to insecticide treatment, spiders were individually anaesthetized by carbon dioxide. The toxicity assay was conducted according to Deng et al. (2006). Two droplets $(0.5 \mu \mathrm{L}$ each) of insecticide solution, by the use of a $5-\mu \mathrm{L}$ microsyringe, were applied to the dorsal abdomen of each spider; distilled water was employed as the control. To reduce possible variation in response to treatments 
168

169

170

171

172

173

174

175

176

177

178

179

180

181

182

183

184

185

186

187

caused by differences in sex, spiders were randomly selected. After insecticide application, spiders

were kept in Petri dishes in which one or two pieces of moist sponge were used to maintain

humidity. Twenty individuals were used for each treatment and the procedure was triplicated.

Spider mortality after $48 \mathrm{~h}$ was calculated as: (number of dead spiders / total number of spiders) $\times$ $100 \%$.

\section{Assays of enzyme activity}

We randomly collected three surviving 3rd-instar E. obliqua larvae from each TS solution and the procedure was repeated four times. Larvae were weighed and placed in a glass homogenizer in which physiological saline $(\mathrm{w} / \mathrm{v}=1: 9)$ was used for homogenization. Samples were centrifuged at $10,000 \times g$ for $10 \mathrm{~min}$ at $4{ }^{\circ} \mathrm{C}$. The supernatant from this final centrifugation was used to determine enzyme activities and protein concentration of each sample.

GST, CES, AChE and POD activities were determined by the use of commercial assay kits (Nanjing Jiancheng Bioengineering Institute, Nanjing, Jiangsu China) according to the manufacturer's instructions. GST, CES, AChE and POD activities were assayed in units of U/mg.

Sample protein concentrations were estimated using the method described by Bradford (1976).

Bovine serum albumin was used for the calibration curve. Detections were performed at $595 \mathrm{~nm}$ emitted by a microplate reader with SoftMax Pro 6.3 software (Molecular Devices Corporation, Sunnyvale, CA, USA). 


\section{Comparative controlling efficacy of $\mathbf{3 0 \%}$ TS (w/v) and chemical}

189

190

191

192

193

194

195

196

197

198

199

200

201

202

203

204

205

206

207

208

\section{insecticides against the $E$. obliqua larvae in tea plantation}

To evaluate the controlling efficacy of $30 \%$ TS along with $10 \% \mathrm{Bi}$ EC (at the recommended

dose of $7.5 \mathrm{~g}^{\mathrm{a} . i .} \mathrm{ha}^{-1}$ ) and $50 \%$ Di EC (at the recommended dose of $45 \mathrm{~g}$ a.i. ha ${ }^{-1}$ ) against $E$.

obliqua larvae, field trials were conducted on dry days from June to July 2015 in Wang Dazhen

tea plantation $\left(30.011^{\circ} \mathrm{N}, 114.363^{\circ} \mathrm{E}\right)$ Xianning, Hubei Province, China following a randomized

block design (Roy, Mukhopadhyay \& Gurusubramanian, 2010; Kawada et al., 2014) with three

replicates. Each identical plot $\left(20 \mathrm{~m}^{2}\right)$ was separated by two buffer rows of non-treated tea bushes.

Two rounds of foliar spray were applied by the use of a 16 L capacity knapsack sprayer equipped

with a hollow cone nozzle (droplet diameter $1.2 \mathrm{~mm}$, distance between nozzle and tea leaves was

$30-40 \mathrm{~cm})$ at $750 \mathrm{~L} \mathrm{ha}^{-1}$. We also established untreated control plots which involved application

of clean water. A pre-treatment sampling was carried out in the respective plots on five randomly

selected tea canopies. After spraying, post-treatment sampling took place at 1, 3, 5 and $7 \mathrm{~d}$ in each

treatment plot from 4:00 - 5:00 pm (Beijing time) in the respective plots in the five randomly

selected tea canopies. E. obliqua larvae were sampled from the randomly selected tea canopies,

using a sweep-net (diameter $40 \mathrm{~cm}$ ) by beating the tea canopy 10 times with a stick. To investigate

the safety of $30 \%$ TS to natural enemies (spiders), the spiders were sampled before and 7 days

after insecticide application at five tea canopies per treatment plot. All sampled tea canopies were

of similar size. Sweep-net sampling was used to sample spiders from the tea canopies. The sweep-

net was held beneath the tea canopies, which was struck 5 times with a stick. All spiders were

individually put into $1.5 \mathrm{~mL}$ microcentrifuge tubes containing $100 \%$ ethanol, and then kept on ice 
209

210

211

212

213

214 formula:

215

216

217

218

219

220

221

222

223

224

225

226

227

228

229

until returned to the laboratory (Yang et al., 2017). According to the classification of toxicity issued

by the IOBC (International Organization of Biological Control), the insecticides tested under the

field conditions were classified as $\mathrm{N}$, harmless or slightly harmful $(0-50 \%$ reduction); $\mathrm{M}$, moderately harmful (51 - 75\% reduction); or T, harmful (75\% reduction) (Boller et al., 2005).

Mean population reduction of pests per treatment was calculated using the following

Population reduction $(\mathrm{PR})=[($ Pre-treatment count - Post-treatment count $) /$ Pre-treatment

population count] $\times 100 \%$

Controlling efficacy $(\mathrm{CE})=[(\mathrm{PR}$ of reagent treatment $-\mathrm{PR}$ of clean water treatment $) /(1-\mathrm{PR}$ of clean water treatment)] $\times 100 \%$

\section{Statistical analysis}

The $\mathrm{LC}_{50}$ and its fiducial limits were determined by logistic regression based on the concentration probit-mortality (Finney, 1971). Mortality variables were expressed in percentages and the data transformed to arcsine square root. The mortality differences between larvae and adult spiders, and controlling efficacy and number of spiders were compared by using the leastsignificant difference (LSD) test at the 5\% level of significance. The differences in enzyme activities of larvae were compared by using the unpaired Student's $t$-test at the $5 \%$ level of significance. Statistical analyses were performed using SPSS 20.0 (IBM Corp Version 20.0. IBM SPSS Statistics for Windows. Armonk, NY, USA) and Prism 5 (GraphPad Software, La Jolla, CA, USA) software. 


\section{Results}

232

233

234

235

236

237

238

239

240

241

242

243

244

245

246

247

248

249

250

\section{The toxicity of TS solution to 3rd-instar E. obliqua larvae}

Mortality of 3rd-instar E. obliqua larvae was in direct proportion to the five TS concentrations at $48 \mathrm{~h}$ with values of $13.33 \%, 27.78 \%, 30.0 \%, 43.33 \%$ and $66.67 \%$ (Table 1 ), respectively. The $\mathrm{LC}_{50}$ value of TS solution to the $3 \mathrm{rd}-\mathrm{instar}$ E. obliqua larvae was $164.32 \mathrm{mg} / \mathrm{mL}$.

\section{Toxicity of insecticides to spiders}

As no individuals died in the control test within $48 \mathrm{~h}$ of distilled water treatment, no adjustment for corrected mortality was necessary. The results of toxicity assay are shown in Table 2. The mortality of E. tricuspidata adults in the group where $300 \mathrm{mg} / \mathrm{mL}$ TS solution was used was $16.67 \%$, significantly lower than that in groups where $10 \% \operatorname{Bi~EC~}\left(F_{1,4}=23.63, p<0.01\right)$ and $50 \%$ Di EC $\left(F_{1,4}=62.74, p<0.01\right)$ were used. The mortality of E. albaria adults was $20 \%$, significantly lower than that in groups where $10 \% \mathrm{Bi} \mathrm{EC}\left(F_{1,4}=23.49, p=0.01\right)$ and $50 \%$ Di EC $\left(F_{1,4}=46.83, p<0.01\right)$ were applied.

Effects of 30\% TS (w/v) on enzyme activities in 3rd-instar E. obliqua larvae

After treatment with 30\% TS, the activities of GST in 3rd-instar E. obliqua larvae showed a significant increase at $6 \mathrm{~h}(t$-test, $t=24.84, d f=6, p<0.001), 12 \mathrm{~h}(t$-test, $t=35.89, d f=6, p<$ $0.001)$ and $24 \mathrm{~h}(t$-test, $t=25.01, d f=6, p<0.001)$; they, however, exhibited decrease in the later 
251 period (Fig. 1). There was no significant difference ( $t$-test, $t=-2.18, d f=6, p=0.072)$ between

252 the results with $30 \%$ TS treatment and distilled water treatment at $48 \mathrm{~h}$, while the former (namely

253 results with $30 \%$ TS) was significantly lower than the latter (namely results with distilled water)

254 at $96 \mathrm{~h}$.

255 The $30 \%$ TS solution significantly inhibited ( $t$-test, $p<0.001$ ) the activities of CES in $E$.

256 obliqua 3rd-instar larvae (Fig. 2), and the activities of CES were maintained at a low-level over

257 the experiment period.

258 As shown in Fig. 3, the activities of AChE in E. obliqua 3rd-instar larvae were significantly

259 inhibited ( $t$-test, $p<0.001)$ by $30 \%$ TS during the whole experimental period.

260 After treatment with $30 \%$ TS, the activities of POD in 3rd-instar E. obliqua larvae increased

261 significantly ( $t$-test, $p<0.01$ ) during the whole experimental period. An exception was the $48 \mathrm{~h}$

262 when no significant difference ( $t$-test, $t=0.363, d f=6, p>0.05)$ was observed in comparison to

263 the control (Fig. 4).

264

265 Comparative controlling efficacy of $30 \%$ TS (w/v) and chemical

266 insecticides against the $E$. obliqua larvae in the tea plantation

267 The controlling efficacies of $30 \% \mathrm{TS}, 10 \% \mathrm{Bi}$ EC and 50\% Di EC against the larvae of $E$.

268 obliqua under field conditions are shown in Table 3. Controlling efficacy (CE) was significantly

269 lower $\left(F_{2,6}=16.44, p<0.01\right)$ in plots sprayed with $30 \%$ TS than that in plots sprayed with $10 \%$

$270 \mathrm{Bi}$ EC and 50\% Di EC during the first 3 d period posttreatment. Further, the CE of 30\% TS was

271 equivalent to chemical pesticides at $5 \mathrm{~d}\left(F_{2,6}=1.658, p>0.05\right)$ and $7 \mathrm{~d}\left(F_{2,6}=0.538, p>0.05\right)$, 
272 respectively.

273 We investigated the number of spiders in different trial plots (Table 4). The number of spiders

274 in the plots treated by $30 \%$ TS was higher than that with $10 \% \mathrm{Bi} \mathrm{EC}\left(F_{1,4}=18.00, p<0.05\right)$ and

$27550 \%$ Di EC $\left(F_{1,4}=16.00, p<0.05\right)$. In terms of IOBC categories for spiders, treatments of clean

276 water and 30\% TS were classified as N (harmless or slightly harmful), whereas 10\% Bi EC and

$27750 \%$ Di EC treatments were classified as M (moderately harmful).

Discussion

280 Control of E. obliqua larvae has been mainly achieved by using synthetic chemical insecticides; however, these insecticides are extremely toxic to non-target organisms and the environment (Potter et al., 2010). In this study, we investigated the toxicity and controlling efficacy of $30 \%$ TS against E. obliqua larvae in the field in order to evaluate its use as a new and natural insecticide.

TS has been used for managing pests because of its insecticidal properties, which include stomach poisoning and odor repellence (Yang \& Zhang, 2012; Cai et al., 2016). In our study, 30\% TS showed insecticidal activities, causing dose-dependent mortality (66.67\%) in 3rd-instar $E$. obliqua larvae. Our results were in accordance with Chen et al. (1996), who demonstrated that $25 \%$ active ingredient of TS-D solution significantly increased larval mortality in the cabbage butterfly (Pieris rapae). A similar result was demonstrated by Rizwan-ul-Haq et al. (2009), who reported that TS showed increased efficiency against Spodoptera when combined with Bacillus thuringiensis Kurstaki. In addition, Bandeira et al. (2013) reported that ethanolic extracts of the 
293 flowers and fruits of Muntingia calabura were toxic to diamondback moth (Plutella xylostella)

294 larvae, which can partly support our findings.

295 The beneficials E. tricuspidata and E. albaria are predators of the larvae of E. obliqua, and

296

297

298

299

300

301

302

303

304

305

306

307

308

309

310

311

312

313

thereby important non-target species in tea plantation can easily be affected by insecticides.

Susceptibilities of these species to the $30 \% \mathrm{TS}, 10 \% \mathrm{Bi}$ EC and 50\% Di EC were assessed in this study. After 48 h, the mortalities of E. tricuspidata and E. albaria which were treated with $30 \%$ TS were significantly higher than those in groups where clean water was applied, while being significantly lower than the mortalities of the two species treated with $10 \% \mathrm{Bi}$ EC and $50 \% \mathrm{Di}$ EC (Table 2). These results indicated that in the laboratory 30\% TS which exerted lethal effect on the two spider species was less harmful than the two chemical insecticides. It is clear that acute toxicity tests do not reflect the full range of effects of a compound on an organism. Our study mainly focused on acute toxicity tests which can reveal details of intoxication but often underestimate mortality in comparison with field studies, which only take into account one route of uptake (Wiles \& Jepson, 1992; Pekár, 2012). The effects that an insecticide has on a beneficial species in the field are complex processes involving both susceptibility and exposure, with exposure being a multidimensional process (John, Paul \& Daniel, 1995). Vânia et al. (2015) demonstrated that the acute toxicity of botanical insecticides might involve delayed effects. In addition, insecticides affect virtually all life-history trails of spiders (Pekár, 2012), whereas the long-term effects of TS on these spiders are currently unknown.

Our findings also indicated that 30\% TS exerted remarkable effects on the activities of detoxification enzymes. Insect resistance is determined by the activities of detoxifying enzymes 
314 and decreased target sensitivity to chemical pesticides (Felton \& Summers, 1995; Potter et al.,

315 2010). The changes usually involve increased detoxification enzyme activities and introduction of

316 additional isoforms (Miao et al., 2016). Increased activity of detoxifying enzymes in insects

317 represents a response to intoxication with insecticides or xenobiotics (Singh \& Singh, 2000;

318 Serebrov et al., 2006; Gopalakrishnan et al., 2011). Rizwan-ul-Haq et al. (2009) evaluated the

319 bioactivities of TS solution in Spodoptera exigua (Lepidoptera: Noctuidae), which provides some

320 helpful information about activities of enzymes against TS which is involved in the resistance

321 mechanism in insects. In this study, we found that the activities of GST significantly increased

322 during the initial period following TS treatment, which suggests that this enzyme may act to

323 detoxify TS. Meanwhile, the activities of CES decreased significantly. In the case of CES, there

324 are two mechanisms of resistance. One is that the over-expressed esterase proteins work like

325 "sponges" to sequester insecticide molecules rather than hydrolyzing them (Chevillon et al. 1999).

326 The other mode of resistance results from changes in the enzymatic properties of CES, specifically,

327 increased activity towards insecticides and decreased activity towards generic substrates (Feng et

al., 2011). Therefore, the inhibition of CES in our study may result in obstruction of CES to

degrade or sequester TS. We speculated that TS may increase susceptibility of E. obliqua larvae

to the insecticide by inhibiting CES activities. AChE is a key enzyme in the nervous system of

various organisms, which can terminate nerve impulses by catalyzing the hydrolysis of the

neurotransmitter acetylcholine (Wang et al., 2004; Senthil et al., 2008). It is well known that altered

$\mathrm{AChE}$ is one of the main mechanisms of resistance in many insect pests (Serebrov et al., 2006).

Our study showed that AChE activities decreased significantly. We inferred that $30 \%$ TS inhibited 
335 the AChE activities, thus causing accumulation of ACh at the synapses. That explains the reason

336 why the post-synaptic membrane is in a state of permanent stimulation. This result in insect

337 paralysis, ataxia, general lack of co-ordination in the neuromuscular system, and eventual death

338 (Singh \& Singh, 2000). POD is the key antioxidant enzyme that can be quickly up-regulated in response to natural penetrating xenobiotics (Wu et al., 2011), and the increase of POD activities is related to pesticide resistance and melanization in insects (Terriere, 1984; Potter et al., 2010). It is shown that POD activities increased over the whole experimental period, except $48 \mathrm{~h}$. We assumed that the enhanced activities of POD are associated with the elimination of ROS. Large quantities of generated ROS can rapidly denature a wide range of biomolecules, thereby threatening virtually all cellular processes and leading to insect death (Felton \& Summers, 1995).

We found that the enzymatic defense against TS assault in 3rd-instar E. obliqua larvae was generally activated. Our results reveal that the perturbation of enzyme activities by TS seems to be one of the underlying modes of action. In addition, several studies documented another probable mode of action of saponins involving interaction with membrane cholesterol, which causes membrane destabilization and provokes cell death (Sung et al., 1995; Hu, Konoki \& Tachibana, 1996; Chaieb et al., 2007). This interaction structurally modified the phospholipid double layer which would be at the origin of disturbances of cellular exchanges leading to cytotoxicity. Chaieb et al. (2007) by the use of histological methods, demonstrated a cytotoxic effect of crude saponic extract on the fat body of Spodoptera larvae, and cell destruction of the foregut and gastric caeca of Schistocerca. The same results were reported by Gögelein et al. (1984) and Hu et al. (1996). Therefore, TS exerted multiple modes of action involving enzymatic and physiological 
356

357

358

359

360

361

362

363

364

365

366

367

368

369

370

371

372

373

374

375

376

perturbation on the 3rd-instar E. obliqua larvae.

The effectiveness of $30 \%$ TS and two types of chemical insecticides against E. obliqua larvae in the field were investigated in this study. As a botanical production, the controlling efficacy of $30 \%$ TS was exceeded by $10 \%$ Bi EC, $50 \%$ Di EC at $5 \mathrm{~d}$ and $7 \mathrm{~d}$, although the difference was not significant (Table 2). A previous study proposed that natural enemies should be the first consideration in any pest management intervention (Koul \& Dhaliwal, 2003). Any integrated approach to pest management must be compatible with natural enemy conservation (Amoabeng et al, 2013). Yang et al. (2017) employed comprehensive indices for evaluating the predation of $E$. obliqua by nine common spider species in Chinese tea plantations. Although the pooled average number of spiders with TS treatment was significantly lower than that with clean water application (Table 4) after $7 \mathrm{~d}$ of reagent application in this study, we supposed that this lower abundance of spiders in experimental plots may be due to reduced prey availability (Sunderland, 1992; Markó et al., 2009). Because TS exerts strong fungicidal activity, it can reduce the abundance of fungi. The reduction in levels of fungi may reduce the abundance of mycetophagous pests such as springtails and some beetles, thus changing the prey availability for spiders (Sunderland, 1992).

Direct evidence of this has not been reported so far. However, pyrazophos applied in the field decreased spider abundance (Volkmar \& Wetzel, 1993), although laboratory tests showed that this fungicide is harmless to spiders (Mansour, Heimbach \& Wehling, 1992). Peng et al. (2017) have reported that $30 \%$ TS exerted a significantly lower repellent rate to spiders compared with chemical insecticides, which could partly support our results. Our results indicated that $30 \%$ TS should be placed in the class $\mathrm{N}$ (harmless or slightly harmful) of IOBC categories for natural 
377 enemies, namely spiders. Therefore, the distribution of spiders can indicate that TS is relatively

378 less harmless than chemical insecticides. In addition, the procedure for preparation of $30 \%$ TS is

379 simple, which only involves the use of water, TS production is cheap and TS is readily available.

380 Our findings suggest a perspective for controlling E. obliqua larvae without the use of chemical

381 insecticides. Using TS to control E. obliqua larvae would help the tea industry in many ways, such

382 as freeing tea products of residues, reducing pesticide load, as well as guaranting cost effectiveness

383 and customer satisfaction (Roy, Mukhopadhyay \& Gurusubramanian, 2010).

384

385

Conclusion

In conclusion, our results indicated that $30 \% \mathrm{TS}$ as a new alternative biocontrol insecticide,

has significant potential against the E. obliqua larvae. It involves in multiple modes of action and

exerts only slightly harmful effects on the natural enemies such as spiders in field applications. As

a natural product that is abundant in tea plantations, 30\% TS could be effectively utilized in the

IPM envisaged for tea.

\section{Acknowledgement}

We are grateful to Wang Dazhen tea plantation for giving permission to conduct the field 
References

404 Abou-Fakhr H, Zournajian EMH, Talhouk S. 2001. Efficacy of extracts of Melia azedarach L. callus, leaves and fruits against adults of the sweetpotato whitefly Bemisia tabaci (Hom., Aleyrodidae). Journal of Applied Entomology 125:483-488. DOI: 10.1046/j.14390418.2001.00577.x.

408

409

410

411

Amoabeng BW, Gurr GM, Gitau CW, Nicol HI, Munyakazi L, Stevenson PC. 2013. Tri-trophic insecticidal effects of African plants against cabbage pests. PLOS ONE 8:e78651. DOI: 10.1371/journal.pone.0078651.

Bandeira GN, Da Camara CAG, De Moraes MM, Barros R, Muhammad S, Akhtar Y. 2013. Insecticidal activity of Muntingia calabura extracts against larvae and pupae of diamondback, Plutella xylostella (Lepidoptera, Plutellidae). Journal of King Saud University-Science 25:83-89. DOI: $10.1016 / j . j k s u s .2012 .08 .002$.

Beloti VH, Alves GR, Araújo DFD, Picoli MM, Moral RA, Demétrio CGB, Yamamoto PT. 2015. Lethal and sublethal effects of insecticides used on Critus, on the Ectoparasitoid Tamarixia radiata. PLoS ONE 10:e0132128. DOI: 10.1371/journal.pone.0132128.

Boller EF, Vogt H, Ternes P, Malavolta C. 2005. Working document on selectivity of pesticides 
419

420

421

422

423

424

425

426

427

(2005). IOBCwprs: Commission on IP Guidelines. Available at http://www.iobcwprs.org/ip_ipm/03021_IOBC_WorkingDocumentPesticides_Explanations.pdf (accessed on 4 October 2017).

Bourguet D, Genissel A, Raymond M. 2000. Insecticide resistance and dominance levels. Journal of Economic Entomology 93:1588-1595. DOI:10.1603/0022-0493-93.6.1588.

Bradford MM. 1976. A rapid and sensitive method for the quantitation of microgram quantities of protein utilizing the principle of protein-dye binding. Analytical Biochemistry 72:248-254. DOI: 10.1016/0003-2697(76)90527-3.

Brattsten LB. 1988. Potential role of plant allelochemicals in the development of insecticide resistance. Bell System Technical Journal 6:187-216.

Cai H, Bai Y, Wei H, Lin S, Chen YX, Tian HJ, Gu XJ, Murugan K. 2016. Effects of tea saponin on growth and development, nutritional indicators, and hormone titers in diamondback moths feeding on different host plant species. Pesticide Biochemistry and Physiology 131:53-59. DOI: $10.1016 /$ j.pestbp.2015.12.010.

Chaieb I, Trabelsi M, Ben HKM, Ben HMH. 2007. Histological effects of cestrum parqui saponins on Schistocerca gregaria and Spodoptera littoralis. Journal of Biological Sciences 7:95-101.

Chaieb I. 2010. Saponins as insecticides: a review. Tunisian Journal of Plant Protection 5:39-50.

Chen J, Zhang S, Yang X. 2012. Control of brown rot on nectarines by tea polyphenol combined with tea saponin. Crop Protection 45:29-35. DOI: 10.1016/j.cropro.2012.11.006.

Chen SR, Li GT, Lai JH, Li X, Zhang YL. 1996. Study of tea saponin TS-D insecticidal effects on cabbage butterfly (in Chinese with English abstract). Plant Protection 22:27-28. 
440 Chen YF, Chen ZH, Song CQ, Xu HZ. 2004. Review on the investigation and protection

441

442

443

444

445

446

447

448

449

450

451

452

453

454

455

456

457

458

459

460

measurement of spiders in Chinese tea gardens (in Chinese with English abstract). Acta Arachnologica Sinica 13:125-128.

Chermenskaya TD, Stepanycheva EA, Shchenikova AV, Chakaeva AS. 2010. Insectoacaricidal and deterrent activities of extracts of Kyrgyzstan plants against three agricultural pests. Industrial Crops and Products 32:157-163. DOI:10.1016/j/indcrop.2010.04.009.

Chevillon C, Raymond M, Guillemaud T, Lenormand T, Pasteur N. 1999. Population genetics of insecticide resistance in the mosquito Culex pipiens. Biological Journal of the Linnean Society 68:147-157. DOI: bij1.1999.0335.

Das S, Roy S, Mukhopadhyay A. 2010. Diversity of arthropod natural enemies in the tea plantations of North Bengal with emphasis on their association with tea pests. Current Science 99:1457-1463.

De Geyter E, Lambert E, Geelen D, Smagghe G. 2007. Novel advances with plant saponins as natural insecticides to control pest insects. Pest Technology 1:96-105.

Deng LL, Dai JY, Cao H, Xu MQ. 2006. Effects of an organophosphorous insecticide on survival, fecundity and develepment of Hylyphantes Graminicola (Sundevall) (Araneae: Linypgiidae). Enviromental Toxicology and Chemistry 25:3073-3077. DOI: 10.1897/06-194R.1.

Ehi-Eromosele CO, Nwinyi O, Ajani OO. 2013. Integrated pest management. In: Soloneski S, Larramendy $\mathrm{M}$ ed. Weed and Pest Control - Conventional and New Challenges. Rijeka: InTech, 105-116.

Felton GW, Summers CB. 1995. Antioxidant Systems in insects. Archives of Insect Biochemistry 
and Physiology 29:187-197. DOI: 10.1002/arch.940290208.

462 Cui F, Lin Z, Wang HS, Liu SL, Chang HJ, Gerald R, Qiao CL, Michel R, Kang L. 2011. Two single mutations commonly cause qualitative change of nonspecific carboxylesterases in insects. Insect Biochemistry and Molecular Biology 41:1-8. DOI: 10.1016/j.ibmb.2010.09.004.

466

467

468

469

470

471

472

473

474

475

476

477

478

479

480

481

Feng J, Tang H, Chen DZ, Li L. 2013. Monitoring and risk assessment of pesticide residues in tea samples from China. Human and Ecological Risk Assessment 21:169-183. DOI: 10.1080/10807039.2014.894443.

Finney DJ. 1971. Probit Analysis: 3rd ed. Cambridge: Cambridge University Press.

Gögelein H, Hüby A. 1984. Interaction of saponin and digitonin with black lipid membranes and lipid monolayers. Biochimica et Biophysica Acta 773:32-38.

Gopalakrishnan S, Chen FY, Thilagam H, Qiao K, Xu WF, Wang KJ. 2011. Modulation and interaction of immune-associated parameters with antioxidant in the immunocytes of crab Scylla paramamosain challenged with lipopolysaccharides. Evidence-based Complementary and $\quad$ Alternative $\quad$ Medicine $\quad(1741-427 \mathrm{X}): 824962 . \quad$ DOI: 10.1146/annurev.en.29.010184.000443

Gurusubramanian G, Rahman A, Sarmah M, Roy S, Bora S. 2008. Pesticide usage pattern in tea ecosystem, their retrospects and alternative measures. Journal of Environmental Biology 29:813-826.

Hao ZS, Guo JL, Peng Y, Zhang JC. 2011. Measurement of toxicity of botanical insecticide "Chachongqing" to five species pests and three natural enemies of pests (in Chinese with 
483

484

485

486

487

488

489

490

491

492

493

494

495

496

497

498

499

500

501

502

Harmatha J, Mauchamp B, Arnault C, Sláma K. 1987. Identification of a spirostane-type saponin in the flowers of leek with inhibitory effects on growth of leek-moth larvae. Biochemical Systematics and Ecology 15:113-116. DOI: 10.1016/03051978(87)90089-5.

Hazarika LK, Puzari KC, Wahab S. 2001. Biological Control of Tea Pests. New York: Plenum Press.

Hu C, Zhu JQ, Ye GY, Hong J. 1994. Ectropis obliqua Prout, a serious geometrid pest of tea bush in east china. Shanghai: Shanghai Scientific and Technical Publishers.

Hu M, Konoki K, Tachibana K. 1996. Cholesterol independent membrane disruption caused by triterpenoid saponins. Biochimica et Biophysica Acta 1299:252-258.

Isman MB. 2006. Botanical insecticides, deterrents, and repellents in modern agriculture and an increasingly regulated world. Annual Review of Entomology 51:45-66. DOI: 10.1146/annurev.ento.51.110104.151146.

Jacobsen BJ, Zidack NK, Larson BJ. 2004. The role of Bacillus-based biological control agents in integrated pest management systems: plant diseases. Phytopathology 94:1272-1275. DOI: 10.1094/PHYTO.2004.94.11.1272.

John DS, Paul CJ, Daniel FM. 1995. Limitations to use of topical toxicity data for predictions of pesticide side effects in the field. Journal of Economic Entomology 88:1081-1088. DOI: 10.1093/ee/26.4.763.

Karban R, Agrawal AA. 2002. Herbivore offense. Annual Review of Ecology and Systematics 33:641-664. DOI: 10.1146/annurev.ecolsys.33.010802.150443. 
503 Kawada H, Dida GO, Ohashi K, Kawashima E, Sonye G, Njenga SM, Mwandawiro C, Minakawa

504 N. 2014. A small-scale field trial of pyriproxyfen-impregnated bed nets against pyrethroid-

505 resistant Anopheles gambiae s.s. in western Kenya. PLoS ONE 9:e111195. DOI:

506 10.1371/journal.pone.0111195.

507

Koul O, Dhaliwal G. 2003. Predators and Parasitoids. New York: Taylor \& Francis Press.

508

509

510

511

512

513

514

515

516

517

518

519

520

521

522

523

Liang P, Gao XW, Zheng BZ. 2003. Genetic basis of resistance and studies on cross-resistance in a population of diamondback moth, Plutella xylostella (Lepidoptera: Plutellidae). Pest Management Science 59:1232-1236. DOI: 10.1002/ps.760.

Liu CY. 2014. Control efficacy of 25\% thiamethoxam and 25\% diafenthiuron on green leafhopper (Empoasca pirisuga) (in Chinese). Modern Horticulture 17:115-116.

Liu MY, Miao YX, Tan RR, Zhang JC. 2012. Pesticidal efficacy of 20\% Chachongqing on the main pests in tea garden (in Chinese with English abstract). Hubei Agricultural Sciences 51:1778-1780.

Ma L, Li ZQ, Bian L, Cai XM, Luo ZX, Zhang YJ, Zong MC. 2016. Identification and comparative study of chemosensory genes related to host selection by legs transcriptome analysis in the tea geometrid Ectropis obliqua. PLoS ONE 11:e0149591. DOI:10.1371/journal.pone.0149591.

Markó V, Keresztes B, Fountain MT, Cross JV. 2009. Prey availability, pesticides and the abundance of orchard spider communities. Biological Control 48:115-124. DOI: 10.1016/j.biocontrol.2008.10.002.

Martínez LC, Plata-Rueda A, Zanuncio JC, Serrão JE. 2015. Bioactivity of six plant extracts on 
524

525

526

527

528

529

530

531

532

533

534

535

536

537

538

539

540

541

542

543

adults of Demotispa neivai (Coleoptera: Chrysomelidae). Journal of Insect Science 15:1-5.

DOI: $10.1093 /$ jisesa/iev021.

Mansour F, Heimbach U, Wehling A. 1992. Effects of pesticide residues on ground-dwelling lycosid and micryphantid spiders in laboratory tests. Phytoparasitica 20:195-202. DOI: 10.1007/BF02980841.

Miao J, Cao GC, Li YB, Tu XB, Wang GJ, Nong XQ, Whitman DW, Zhang ZH. 2016. Biochemical basis of synergism between pathogenic fungus Metarhizium anisopliae and insecticide chlorantraniliprole in Locusta migratoria (Meyen). Scientific Reports 22:28424. DOI: $10.1038 /$ srep28424.

Murphy ST, Briscoe BR. 1999. The red palm weevil as an alien invasive: biology and the prospects for biological control as a component of IPM. Biocontrol News and Information 20:35N$46 \mathrm{~N}$.

Oehmichen M, Besserer K. 1982. Forensic significance of acetylcholine esterase histochemistry in organophosphate intoxication. Zeitschrift Für Rechtsmedizin Journal of Legal Medicine 83:149-165.

Pekár S. 2012. Spiders (Araneae) in the pesticide world: an ecotoxicological review. Pest Management Science 68:1438-1446. DOI 10.1002/ps.3397.

Peng JT, Peng Y, Zeng C. 2017. Determination of the bioactivities of tea saponin solution to 3rdinstar larvae of Ectropis obliqua and two species of spider (in Chinese with English abstract). Acta Arachnologica Sinica 26:114-118.

544 Potter DA, Redmond CT, Meepagala KM, Williams DW. 2010. Managing earthworm casts 
(Oligochaeta: Lumbricidae) in turfgrass using a natural byproduct of tea oil (Camellia sp.) manufacture. Pest Management Science 66:439-446. DOI: 10.1002/ps.1896.

547 Rizwan-ul-Haq M, Hu QB, Hu MY, Zhong G, Weng Q. 2009. Study of destruxin B and tea saponin, their interaction and synergism activities with Bacillus thuringiensis kurstaki against Spodoptera exigua (Hübner) (Lepidoptera: Noctuidae). Applied Entomology and Zoology

Roy S, Mukhopadhyay A, Gurusubramanian G. 2010. Field efficacy of a biopesticide prepared from Clerodendrum viscosum Vent. (Verbenaceae) against two major tea pests in the sub Himalayan tea plantation of North Bengal, India. Journal of Pest Science 83:371-377. DOI:

Rutledge CE, Fox TB, Landis DA. 2004. Soybean aphid predators and their use in integrated pest 10.1007/s10340-010-0306-5. management. Annals of the Entomological Society of America 97:240-248.

Saha D, Mukhopadhyay A. 2013. Insecticide resistance mechanisms in three sucking insect pests of tea in reference to North-East India; an appraisal. International Journal of Tropical Insect Science 33:46-70. DOI: 10.1017/S1742758412000380.

Senthil NS, Young CM, Yul SH, Hoon PC, Kalaivani K, Duk KJ. 2008. Effect of azadirachtin on acetylcholinesterase (AChE) activity and histology of the brown planthopper Nilaparvata lugens (Stål). Ecotoxicology and Environmental Safety 70:244-250. DOI: 
566

567

568

569

570

571

572

573

574

575

576

577

578

579

580

581

582

583

584

585

586

Galleria mellonella L. (Lepidoptera, Pyralidae) and role of detoxification enzymes in development of insect resistance to entomopathogenic fungi. Biology Bulletin 33:581-586. DOI: $10.1134 / \mathrm{S} 1062359006060082$.

Singh K, Singh DK. 2000. Toxicity to the snail Limnaea acuminata of plant-derived molluscicides in combination with synergists. Pest Management Science 56:889-898. DOI: 10.1002/15264998(200010)56:10<889::AID-PS221>3.0.CO;2-0.

Snyder MJ, Glendining JI. 1996. Causal connection between detoxification enzyme activity and consumption of a toxic plant compound. Journal of Comparative Physiology A 179:255-261.

Sung MK, Kendall WC, Rao AV. 1995. Effect of soybean saponins and Gypsophilla saponins on morphology of carcinoma cells in culture. Food and chemical toxicology 33:357-363.

Sunderland KD. 1992. Effects of pesticides on the population ecology of polyphagous predators. Aspects of Applied Biology 31:19-28.

Terriere LC. 1984. Induction of detoxication enzymes in insects. Annual Review of Entomology 29:771-788. DOI: 10.1146/annurev.en.29.010184.000443.

Vânia MX, Message D, Picanc MC, Chediak M, Paulo AJS, Ramos RS, Martins JC. 2015. Acute toxicity and sublethal effects of botanical insecticides to honey bees. Journal of Insect Science 15:137. DOI: $10.1093 /$ jisesa/iev110.

Volkmar C and Wetzel T. 1993. On the occurrence of insect pests and soil surface spiders (Araneae) in cereal fields and the side effects of some fungicides. Nachrichtenblatt Des Deutschen Pflanzenschutzdienstes 45:233-239.

Wang JJ, Cheng WX, Ding W, Zhao ZM. 2004. The effect of the insecticide dichlorvos on esterase 
587

588

589

590

591

592

593

594

595

596

597

598

599

600

601

602

603

604

605

606

607

activity extracted from the psocids, Liposcelis bostrvchophila and L. entomophila. Journal of Insect Science 4:23-27.

Wiles JA, Jepson PC. 1992. In situ bioassay techniques to evaluate the toxicity of pesticides to beneficial invertebrates in cereals. Aspects of Applied Biology 31:61-68.

Wu GY, Zeng MS, Xia HL, Ma XJ, Wang QS, Wang WJ, Chen ZL. 2013. Security analysis of residual bifenthrin tea plantation. Fujian Journal of Agriculture Sciences 28:366-371.

Wu HH, Liu JY, Zhang R, Zhang JZ, Gao YP, Ma EB. 2011. Biochemical effects of acute phoxim administration on antioxidant system and acetylcholinesterase in Oxya chinensis (Tunberg) (Orthoptera: Acrididae). Pesticide Biochemistry and Physiology 100:23-26. DOI: 10.1016/j.pestbp.2011.01.011.

Xin ZJ, Li XW, Li JC, C ZM, Sun XL. 2016. Application of chemical elicitor (Z)-3-hexenol enhances direct and indirect plant defenses against tea geometrid Ectropis obliqua. Biocontrol 61:1-12. DOI: 10.1007/s10526-015-9692-1.

Yang T, Liu J, Yuan L, Zhang Y, Peng Y, Li D, Chen J. 2017. Main predators of insect pests: screening and evaluation through comprehensive indices. Pest Management Science 73:2302-2309. DOI: 10.1002/ps.4613.

Yang XP, Zhang HQ. 2012. Synergistic interaction of tea saponin with mancozeb against Pestalotipsis theae. Crop Protection 40:126-131. DOI: 10.1016/j.cropro.2012.04.013.

Ye GY, Xiao Q, Chen M, Chen XX, Yuan ZJ, Stanly DW, Hu C. 2014. Tea: Biological control of insect and mite pests in China. Biological Control 68:73-91. DOI: 10.1016/j.biocontrol.2013.06.013. 
608 Zhang GH, Yuan ZJ, Zhang CX, Yin KS, Tang MJ, Guo HW, Fu JY, Xiao Q. 2014. Detecting 609 deep divergence in seventeen populations of tea geometrid (Ectropis obliqua Prout) in China $610 \quad$ by COI. PLoS ONE 9:e99373. DOI: 10.1371/journal.pone.0099373. 


\section{Table $\mathbf{1}$ (on next page)}

Toxicity of TS solution to 3rd-instar Ectropis obliqua larvae

$\mathrm{TS}$, tea saponin; $\mathrm{LC}_{50}$, Lethal concentration 50 , the concentration causing $50 \%$ mortality; $\mathrm{FL}$, fiducial limits $(\mathrm{mg} / \mathrm{mL}) ; \mathrm{SE}$, standard error of the means. Mortalities $(\% \pm \mathrm{SE})$ followed by the same letters represented no significant difference (Least-significant difference test at the $5 \%$ level of significance). 
1 Toxicity of TS solution to 3rd-instar Ectropis obliqua larvae

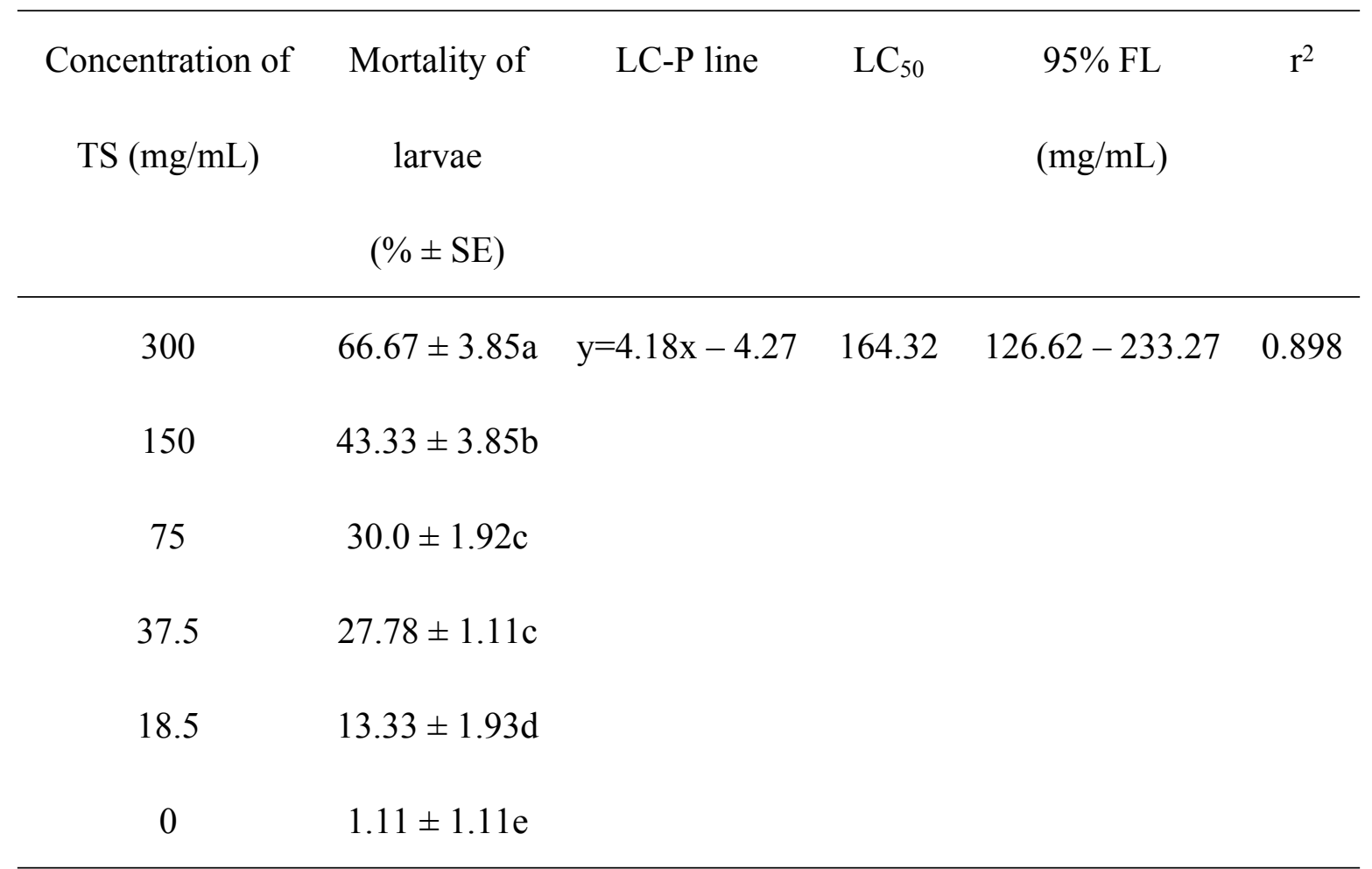

$2 \mathrm{TS}$, tea saponin; $\mathrm{LC}_{50}$, Lethal concentration 50 , the concentration causing $50 \%$ mortality;

3 FL, fiducial limits $(\mathrm{mg} / \mathrm{mL})$; SE, standard error of the means.

4 Mortalities $(\% \pm \mathrm{SE})$ followed by the same letters represented no significant difference (Least-

5 significant difference test at the $5 \%$ level of significance). 


\section{Table 2 (on next page)}

Mortalities of Ebrechtella tricuspidata and Evarcha albaria adults after $48 \mathrm{~h}$ of treatment using different reagents

$\mathrm{Bi}$, bifenthrin EC; Di, diafenthiuron SC; TS, tea saponin. SE, standard error of the means. Mortality $(\% \pm \mathrm{SE})$ followed by the same letters represented no significant difference (Leastsignificant difference test at the $5 \%$ level of significance). 
1 Mortalities of Ebrechtella tricuspidata and Evarcha albaria adults after 48 h of treatment

2 using different reagents

\begin{tabular}{cccc}
\hline Treatment & Concentration & \multicolumn{2}{c}{ Mortality (mean $\pm \mathrm{SE})(\%)$} \\
\cline { 3 - 4 } & $(\mathrm{mg} / \mathrm{mL})$ & E. tricuspidata & E. albaria \\
\hline $10 \%$ Bi EC & 0.01 & $80.00 \pm 5.77 \mathrm{a}$ & $73.33 \pm 3.33 \mathrm{a}$ \\
$50 \%$ Di SC & 1.2 & $43.33 \pm 3.33 \mathrm{~b}$ & $36.67 \pm 6.67 \mathrm{~b}$ \\
TS & 300 & $16.67 \pm 3.33 \mathrm{c}$ & $20.00 \pm 5.77 \mathrm{c}$ \\
Control & & $0 \mathrm{~d}$ & $0 \mathrm{~d}$ \\
\hline
\end{tabular}

3 Bi, bifenthrin EC; Di, diafenthiuron SC; TS, tea saponin. SE, standard error of the means.

4 Mortality $(\% \pm \mathrm{SE})$ followed by the same letters represented no significant difference (Least-

5 significant difference test at the $5 \%$ level of significance). 


\section{Table 3(on next page)}

The controlling efficacy of 30\% TS (w/v) and chemical insecticides against the Ectropis obliqua larvae

$\mathrm{Bi}$, bifenthrin; $\mathrm{Di}$, diafenthiuron; $\mathrm{TS}$, tea saponin. SE, standard errors of the means. Within columns, data $(\% \pm \mathrm{SE})$ followed by the same letters represented no significant difference (Least-significant difference test at the $5 \%$ level of significance). 
1 The controlling efficacy of $30 \%$ TS (w/v) and chemical insecticides against the Ectropis

2 obliqua larvae

\begin{tabular}{|c|c|c|c|c|c|}
\hline \multirow{2}{*}{ Treatment } & \multirow{2}{*}{$\begin{array}{c}\text { Dose } \\
\left(\text { g a.i. } \text { ha }^{-1}\right)\end{array}$} & \multicolumn{4}{|c|}{ Controlling efficacy (CE) (Mean \pm SE) $(\%)$} \\
\hline & & $1 \mathrm{~d}$ & $3 \mathrm{~d}$ & $5 \mathrm{~d}$ & $7 \mathrm{~d}$ \\
\hline $10 \% \mathrm{Bi} \mathrm{EC}$ & 7.5 & $71.23 \pm 8.77 \mathrm{a}$ & $85.87 \pm 4.07 \mathrm{a}$ & $60.12 \pm 4.56 \mathrm{a}$ & $49.65 \pm 3.04 \mathrm{a}$ \\
\hline $50 \%$ Di SC & 45 & $56.53 \pm 3.30 \mathrm{a}$ & $83.35 \pm 4.39 \mathrm{a}$ & $61.32 \pm 5.24 \mathrm{a}$ & $52.45 \pm 3.72 \mathrm{a}$ \\
\hline $30 \% \mathrm{TS}$ & 562.5 & $15.93 \pm 2.58 b$ & $49.16 \pm 6.40 b$ & $77.02 \pm 3.93 a$ & $58.87 \pm 4.44 \mathrm{a}$ \\
\hline
\end{tabular}

3 Bi, bifenthrin; Di, diafenthiuron; TS, tea saponin. SE, standard errors of the means.

4 Within columns, data $(\% \pm \mathrm{SE})$ followed by the same letters represented no significant difference

5 (Least-significant difference test at the 5\% level of significance).

6 


\section{Table 4(on next page)}

The toxicity classes of different reagents in spiders in the treatment plots

$\mathrm{Bi}$, bifenthrin; Di, diafenthiuron; TS, tea saponin; Control, water spray. SE, standard errors of the means. PTC: pre-treatment count; PR: population reduction $=[($ PTC $-7 \mathrm{~d}$ count $) /$ PTC $] \times$ $100 \%$; TC, toxicity classes ( $N$, harmless or slightly harmful at the $0-50 \%$ level of PR; $M$, moderately harmful at the $51 \%-75 \%$ level of PR; T, harmful at over the $75 \%$ level of PR). Within columns, the same letters represented no significant difference (Least-significant difference test at the $5 \%$ level of significance). 
1 The toxicity classes of different reagents in spiders in the treatment plots

\begin{tabular}{|c|c|c|c|c|}
\hline \multirow{3}{*}{ Treatment } & \multicolumn{2}{|c|}{ Number of spiders } & \multirow{3}{*}{ PR (\%) } & \multirow{3}{*}{$\mathrm{TC}$} \\
\hline & \multicolumn{2}{|c|}{$($ mean $\pm \mathrm{SE})$} & & \\
\hline & PTC & $7 \mathrm{~d}$ & & \\
\hline $10 \% \mathrm{Bi} \mathrm{EC}$ & $6.33 \pm 0.33 a$ & $2.67 \pm 0.33 \mathrm{~cd}$ & $57.94 \pm 4.82$ & M \\
\hline $50 \%$ Di SC & $5.67 \pm 0.67 \mathrm{a}$ & $2.00 \pm 0.58 \mathrm{~d}$ & $66.27 \pm 5.16$ & M \\
\hline $30 \% \mathrm{TS}$ & $6.67 \pm 0.33 \mathrm{a}$ & $4.67 \pm 0.33 b$ & $29.17 \pm 6.25$ & $\mathrm{~N}$ \\
\hline Control & $6.00 \pm 0.57 \mathrm{a}$ & $6.67 \pm 0.67 \mathrm{a}$ & $-11.42 \pm 5.95$ & $\mathrm{~N}$ \\
\hline
\end{tabular}

2 Bi, bifenthrin; Di, diafenthiuron; TS, tea saponin; Control, water spray. SE, standard errors of the

3 means. PTC: pre-treatment count; PR: population reduction $=[(\mathrm{PTC}-7 \mathrm{~d}$ count $) / \mathrm{PTC}] \times 100 \%$;

$4 \mathrm{TC}$, toxicity classes $(\mathrm{N}$, harmless or slightly harmful at the $0-50 \%$ level of PR; M, moderately

5 harmful at the $51 \%-75 \%$ level of PR; T, harmful at over the $75 \%$ level of PR).

6 Within columns, the same letters represented no significant difference (Least-significant difference

7 test at the 5\% level of significance). 
Figure 1

The effects of 30\% (w/v) TS on GST activity in 3rd-instar larvae of Ectropis obliqua at different times

TS, tea saponin; control: distilled water. Each value represents the mean of three replicates from four parallel experiments. Student's t-test, *, p < 0.05; **, p < 0.01; ***, p < 0.001; ns, no significant differences. The bars represent the standard error.

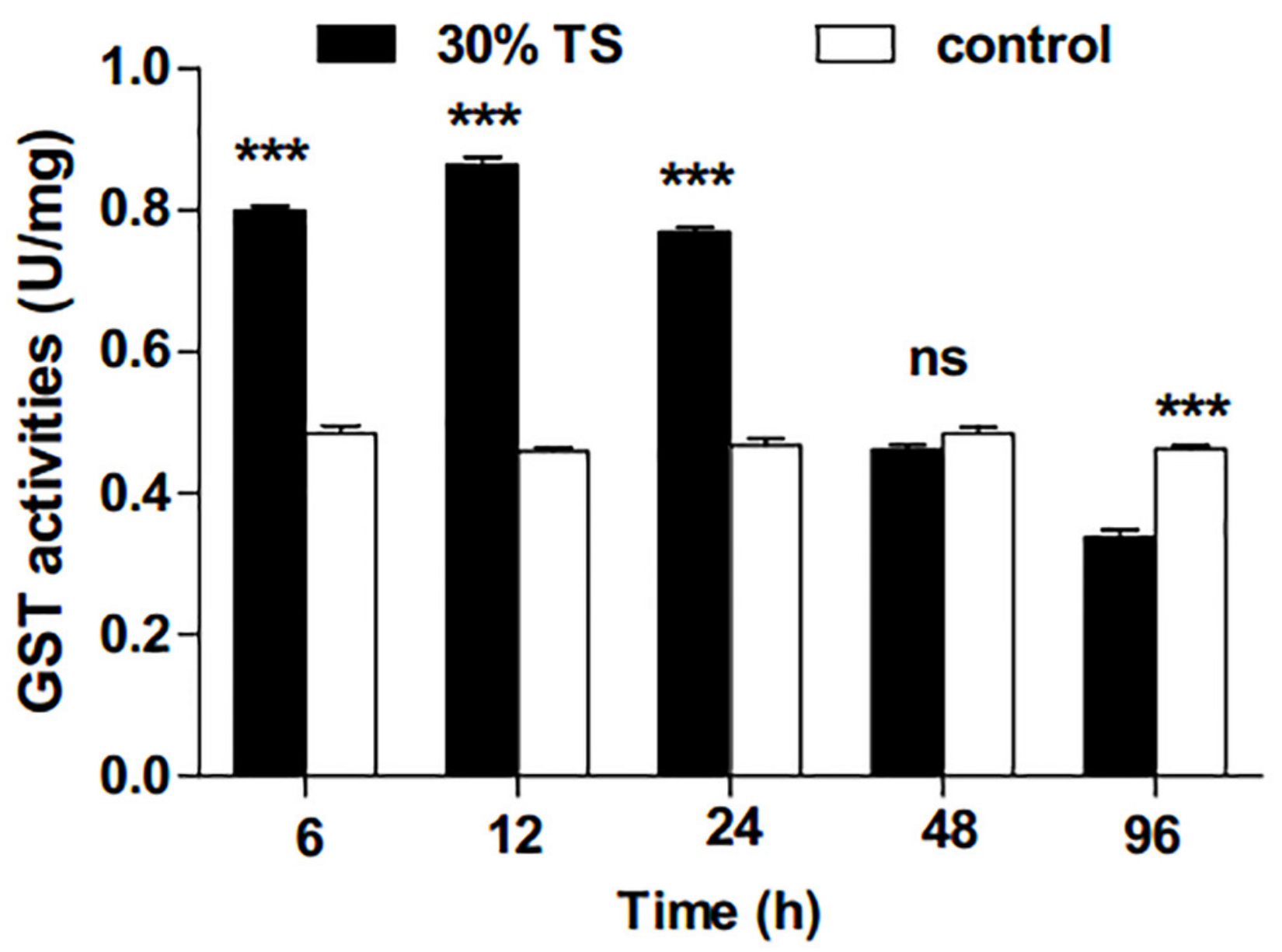


Figure 2

The effects of $30 \%(\mathrm{w} / \mathrm{v})$ TS on CES activity in 3rd-instar larvae of Ectropis obliqua at different times

TS, tea saponin; control: distilled water. Each value represents the mean of three replicates from four parallel experiments. Student's t-test, *, p < 0.05; **, p < 0.01; ***, p < 0.001; ns, no significant differences. The bars represent the standard error.

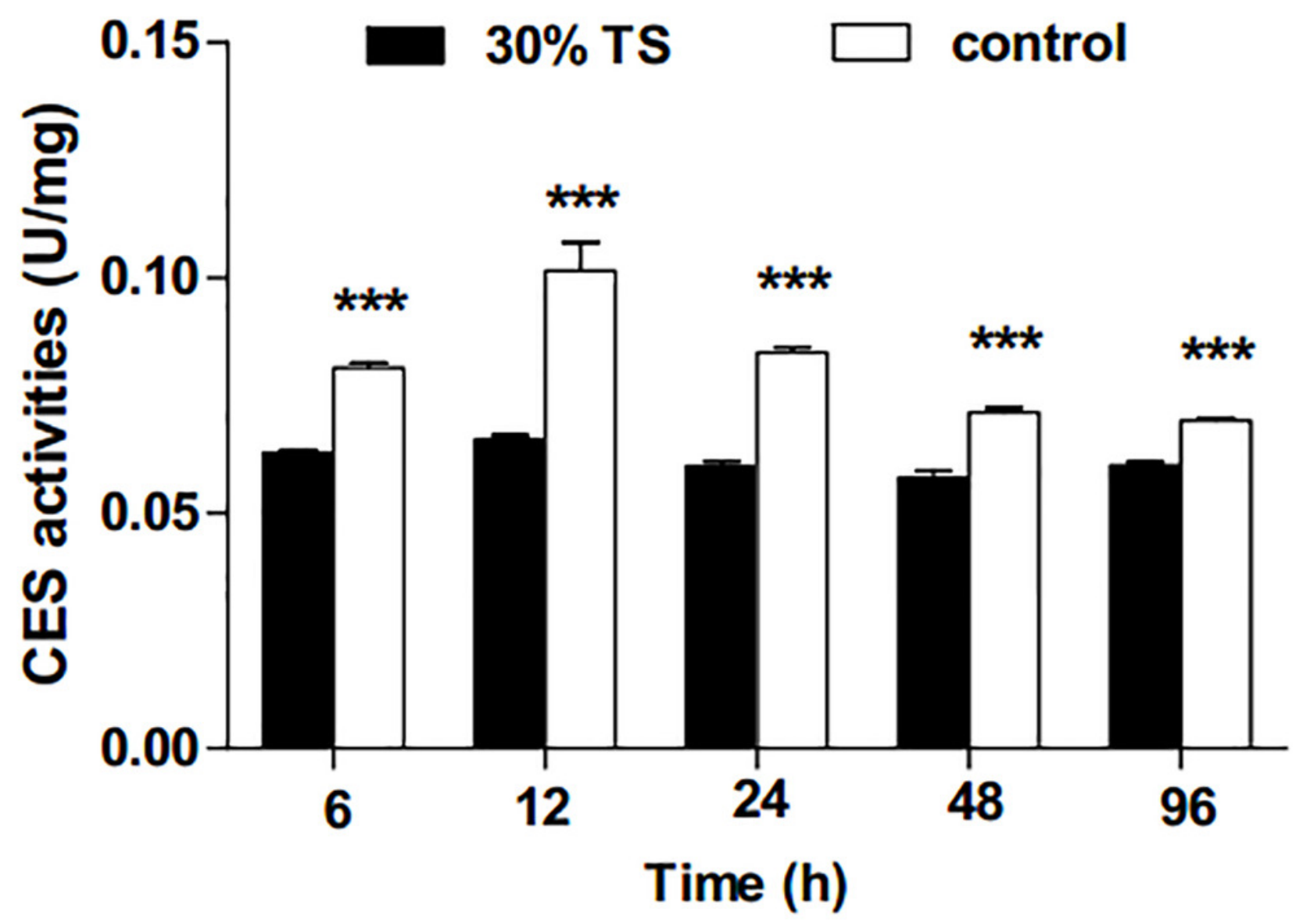


Figure 3

The effects of $30 \%(\mathrm{w} / \mathrm{v})$ TS on AC activity in 3rd-instar larvae of Ectropis obliqua at different times

TS, tea saponin; control: distilled water. Each value represents the mean of three replicates from four parallel experiments. Student's t-test, *, p < 0.05; **, p < 0.01; ***, p < 0.001; ns, no significant differences. The bars represent the standard error.

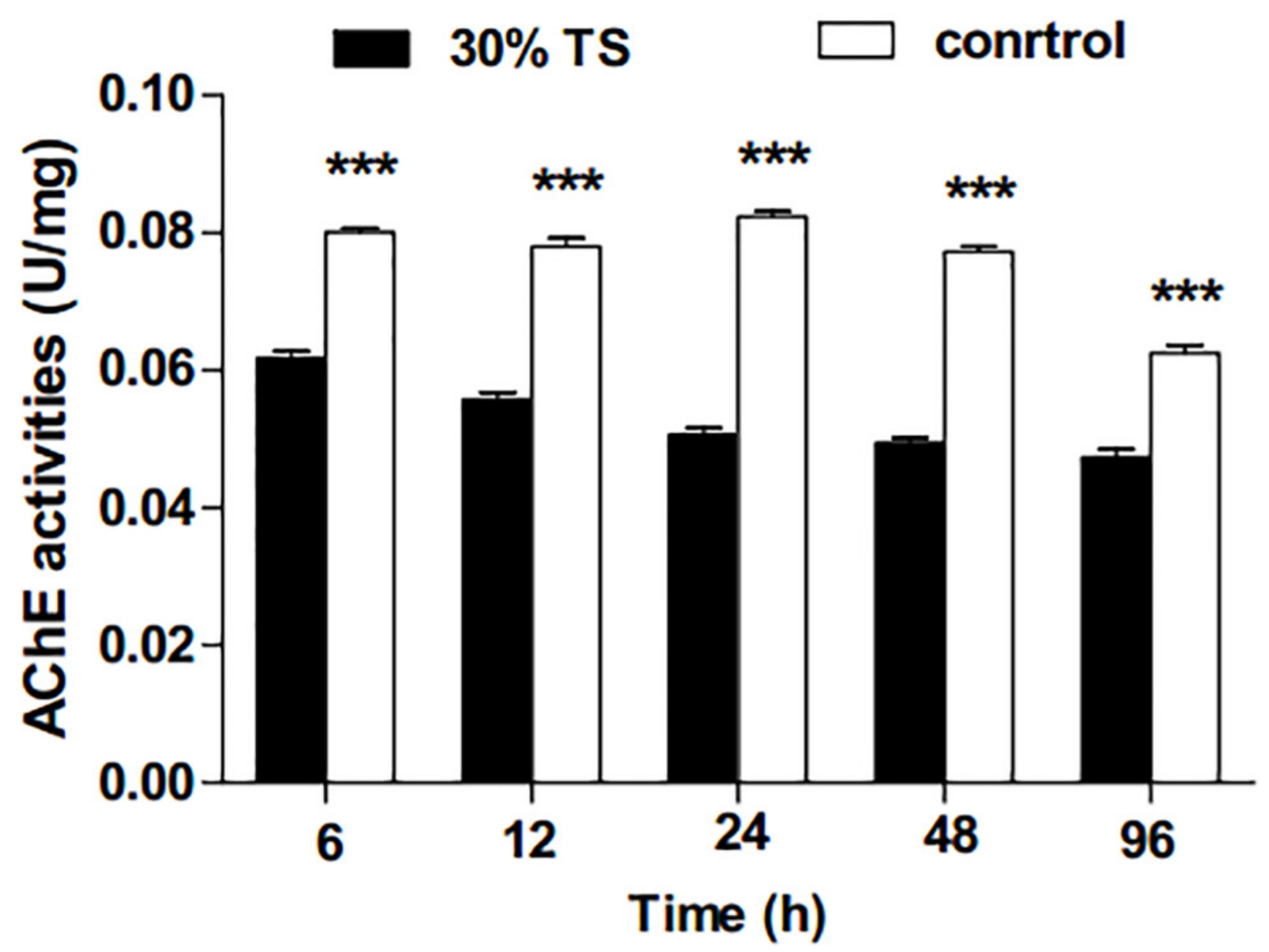


Figure 4

The effects of $30 \%(w / v)$ TS on POD activity in 3rd-instar larvae of Ectropis obliqua at different times

TS, tea saponin; control: distilled water. Each value represents the mean of three replicates from four parallel experiments. Student's t-test, *, p < 0.05; **, p < 0.01; ***, p < 0.001; ns, no significant differences. The bars represent the standard error.

$30 \%$ TS

$\square$ control

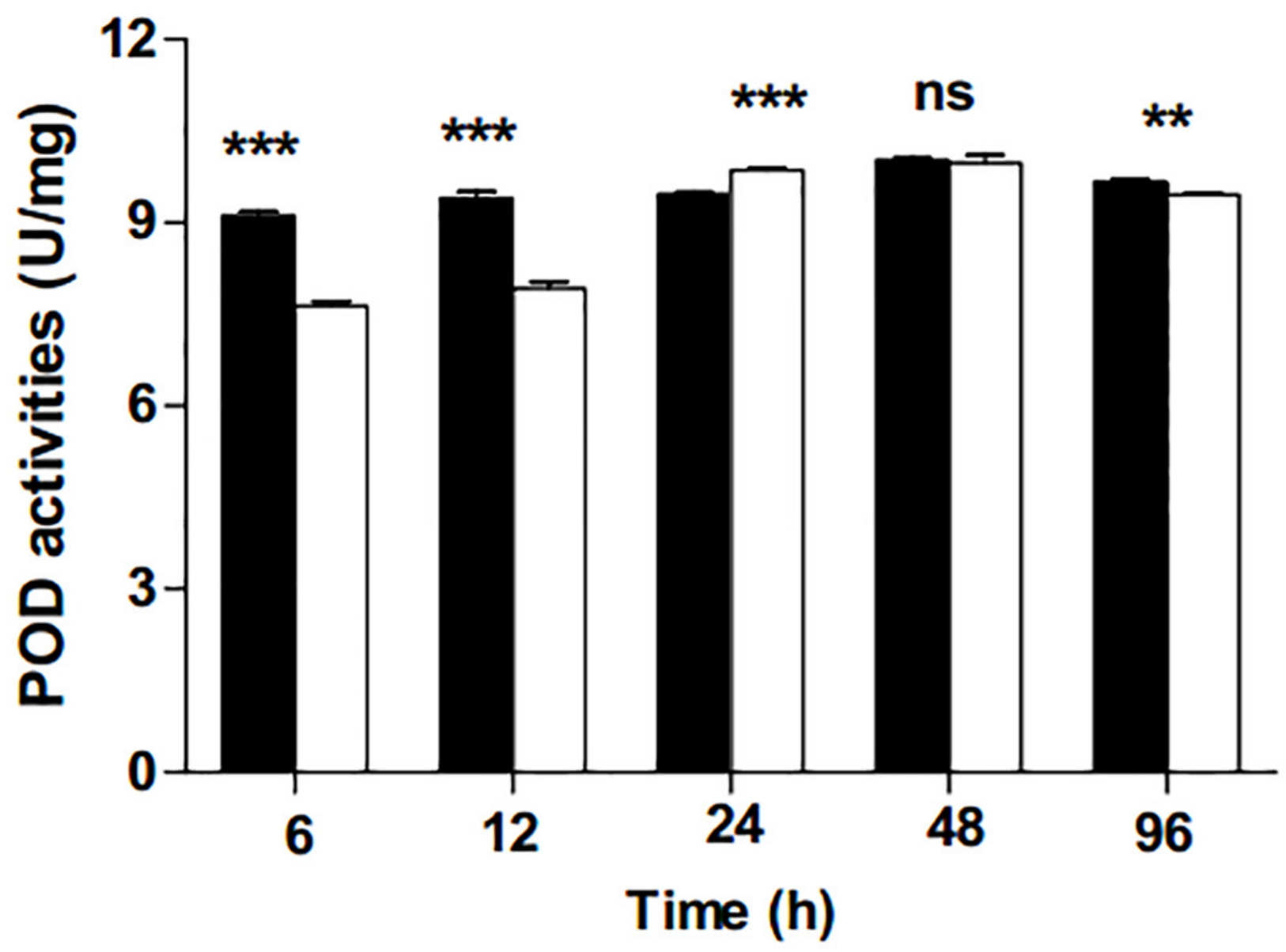

